\title{
Foreign Language Vocabulary Learning and the Type of Processing-Resource Allocation Model
}

\author{
Shusaku Kida \\ Hiroshima University
}

\begin{abstract}
This paper argues the nature of adult foreign or second language (L2) vocabulary learning and points out the importance of word-form learning at the initial stage of vocabulary development. The Type of Processing-Resource Allocation (TOPRA) model is introduced as a prominent theoretical framework to capture it. Finally, some future studies are proposed to reinforce TOPRA-based studies with respect to (1) types of vocabulary processing tasks and (2) dimensions of vocabulary development.
\end{abstract}

Keywords: L2 vocabulary learning, form-meaning connection, the type of processing-resource allocation model, semantic and structural processing, acquisition of word knowledge and fluent processing

\section{Introduction}

It has been acknowledged that the quality and quantity of processing play crucial roles in foreign or second language (L2) vocabulary learning (Hulstijn, 2001). The quality of processing refers to how learners process unfamiliar words (e.g., semantic processing, structural processing), whereas the quantity of processing refers to how many times they process the same words (e.g., exposure frequency). Numerous studies have examined the effects of the two factors (e.g., Eckerth \& Tavakoli, 2012; Joe, 2010; Laufer \& Rozovski-Roitblat, 2011, 2015; Paribakht \& Wesche, 1999; Schmitt, 2008). Yet, the discussion is ongoing, and there is no universally accepted resolution.

This paper focuses on a specific theoretical account of the quality of processing: the Type of Processing-Resource Allocation (TOPRA) model (Barcroft, 2002, 2003). By looking at previous studies, some possible future studies will be proposed to reinforce the TOPRA model and related studies.

\section{The Nature of Foreign/Second Language Vocabulary Learning}

Foreign language vocabulary learning entails at least the following three aspects: word form, meaning, and form-meaning connection (Barcroft, 2003). When it comes to adult foreign language learning, language learners usually already have the semantic representations of most L2 words through their L1 acquisition experience, which helps them understand the meanings of new L2 words 
using the L1 translation of the word in question. Therefore, at the beginning stage of L2 vocabulary development, the primary task is not to learn meaning itself, as the meaning of the word could be understood by the L1 translation (Ellis, 2004; Jiang, 2000; Laufer, 1997; Nation, 2001), but rather to learn the target word form and form-meaning connection.

Another aspect that L2 learners need to develop is fluency. Language learning is not limited to simply memorizing word knowledge mentioned above (i.e., word form, meaning, and form-meaning connection); we also need to be able to use the language fluently. In the field of second language acquisition, Bialystok and Sharwood Smith (1985) once proposed the distinction between language knowledge and its control. The former was explained as "the way in which the language system is represented in the mind of the learner," while the latter was referred to as "the processing system for controlling that knowledge during actual performance" (p. 104).

Similar distinctions have been proposed in L2 vocabulary learning research, such as the distinction between lexical knowledge and lexical competence (Jiang, 2000) and between explicit lexical knowledge and tacit lexical knowledge (Elgort \& Warren, 2014). These proposals emphasize the importance of both the acquisition of word knowledge and the fluent processing of words. For example, according to Jiang, lexical knowledge refers to "the knowledge or information an L2 learner remembers about the form, meaning, grammatical usage, and sociolinguistic use of a word that is stored in a general memory system, rather than integrated into the lexical entry of a word" (p. 65), whereas lexical competence refers to "the semantic, syntactic, morphological, and formal knowledge about a word that has become an integral part of an lexical entry in the mental lexicon and can be retrieved automatically in natural communication" (pp. 65-66). Elgort and Warren (2014) also emphasized the distinction between explicit knowledge (which is measured in conventional tests such as multiple-choice tests or translation with some sort of controlled retrieval of words) and tacit knowledge (which is measured in word processing tasks such as lexical decision and underlies fluent processing of words). Therefore, it has been assumed that successful L2 vocabulary learning includes not only the acquisition of new word knowledge, such as word form and meaning, but also the acquisition of fluent and efficient processing of newly learned words.

As these distinctions show, it is common to assume that L2 vocabulary acquisition consists of multiple stages or aspects. Therefore, in L2 vocabulary learning research, it is crucial to examine vocabulary learning from various perspectives using different types of measurement.

\section{The Type of Processing-Resource Allocation Model}

The levels-of-processing (LOP) framework (Craik \& Lockhart, 1972; Craik $\&$ Tulving, 1975) has been widely used to account for the role of the quality of processing in L2 vocabulary learning research (Laufer \& Hulstijn, 2001). The LOP framework assumes that some levels or depths of processing exist, and that deeper information processing leads to better memory performance. According to the original LOP framework, semantic processing was assumed to be deeper than 
orthographic or phonological processing, and therefore should facilitate memory of the target information.

On the other hand, the TOPRA model proposed by Barcroft $(2002,2003)$ assumes that semantic processing does not necessarily help new L2 word learning. According to this model, L2 learners' processing-resource allocation to L2 word form or meaning corresponds to their learning performance. For example, when L2 learners allocate their processing-resources to unknown L2 word meaning, the likelihood of remembering the (L1-based) meaning increases. Simultaneously, learning of structural aspects, such as word form, is inhibited when overall processing demands are sufficiently high. On the other hand, when L2 learners allocate their processing-resources to the structural aspect (e.g., word form) of the word in question, the possibility that they learn it (e.g., the new L2 word form) increases. The TOPRA model predicts this kind of trade-off between different aspects of L2 vocabulary processing and learning. A series of studies by Barcroft (2002, 2003, 2004, 2009) demonstrated that the TOPRA model offers a better explanation than the LOP hypothesis for adult L2 vocabulary learning.

\subsection{Vocabulary Processing Tasks in Type of Processing-Resource Allocation Studies}

Although the prediction of the TOPRA model has been tested by previous studies, some criticism may be possible. One criticism may be of the ecological validity of vocabulary processing tasks when it comes to foreign/L2 pedagogy in L2 classrooms. For example, Barcroft (2002) presented new L2 Spanish words and their pictures to learners. They were instructed to learn these word-picture pairs in the following conditions: semantic processing, structural processing, and control. In the semantic and structural processing conditions, the participants were asked to remember new L2 words and their pictures while making pleasantness ratings about the meaning of each word as well as while counting the number of letters of each word. In the control condition, there was no such additional task; learners were simply instructed to remember the word-picture pairs. The semantic and structural processing tasks were originally based on LOP research (e.g., Hyde \& Jenkins, 1969) in psychology and were not necessarily intended to be used in L2 pedagogy. Therefore, one may argue that the results of the previous studies do not have direct implications on L2 classroom practice, and that studies with more pedagogically applicable tasks would be necessary when the TOPRA model predictions are applied to foreign/L2 pedagogy.

\subsection{Aspects of Vocabulary Development in Type of Processing- Resource Allocation Studies}

Another possible critique is that the aspects of vocabulary acquisition examined in previous studies are limited. So far, the predictions of the TOPRA model have been tested using the following four measurements: L1 free recall, L2 free recall, L1-to-L2 cued recall, and L2-to-L1 cued recall. They assess whether the L2 learners remember target word forms, meanings, and form-meaning connections.

Vocabulary Learning and Instruction, 8 (1), 76-82. 
For example, after the L2 Spanish word learning session described above in the study by Barcroft (2002), the participants took these four measurements. In the two free recalls (L2 and L1 free recalls), the participants were asked to recall L2 target words or their pictures in L1, respectively. On the other hand, in the two cued recalls, they were asked to produce L2 target words for the presented L1 words in the case of L1-to-L2 cued recall, and vice versa in the case of L2-to-L1 cued recall. It was assumed that L1 and L2 free recalls are relatively pure measurements of the effects of semantic and structural processing, respectively. If the prediction of the TOPRA model is valid, the semantic processing condition should outperform the structural processing condition in the case of L1 free recall, whereas the opposite result should hold good in the case of L2 free recall. The results of Barcroft (2002) were consistent with this prediction. However, as argued above, language acquisition is not limited to simply acquiring new word knowledge such as word form or meaning; it also includes the acquisition of fluent and efficient processing of the newly learned words (Elgort \& Warren, 2014; Jiang, 2000). The four types of recall used in the previous studies seem to measure only acquisition of new word knowledge. Therefore, it is not clear whether the TOPRA model prediction is applicable to the acquisition of fluent processing of learned words.

\section{Some Possible Future Directions}

Thus far, the present paper has described the nature of adult foreign/L2 vocabulary learning and points out that at the beginning stage of L2 vocabulary development, the learning of word form is more important than the learning of meaning. The TOPRA model captures this by proposing a trade-off between the different types of processing and learning as a result of processing-resource allocation. We can further reinforce the results of studies on the TOPRA model by (1) examining the effects of other types of vocabulary processing tasks and (2) assessing other aspects of vocabulary development. Figure 1 shows areas for possible

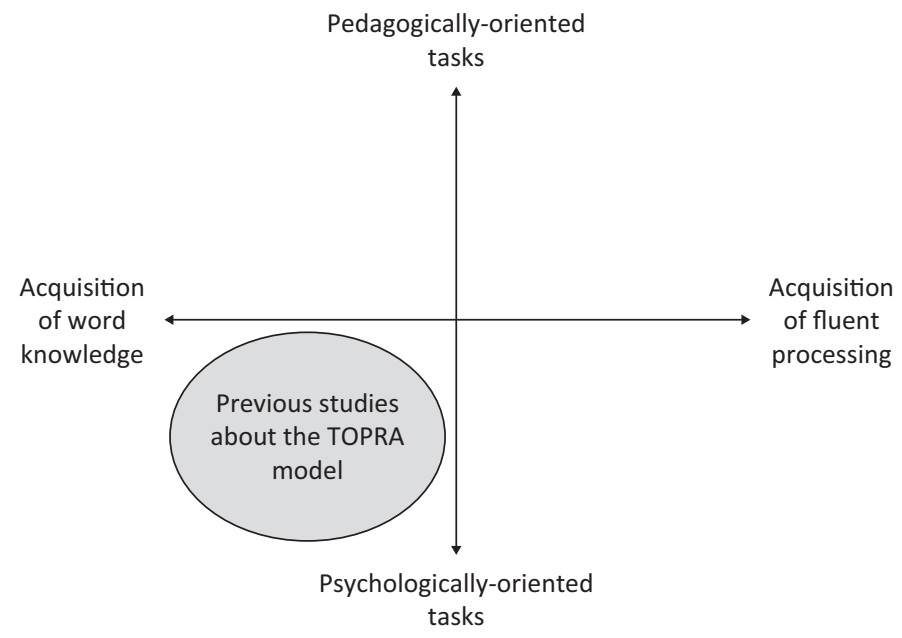

Figure 1. Framework of Previous Studies of the TOPRA Model. 
study of the TOPRA framework in the two dimensions of (1) types of vocabulary processing tasks (vertical) and (2) aspects of vocabulary development (horizontal).

According to this framework, as Figure 1 shows, previous studies regarding the TOPRA model only focused on one of four possible research areas. Future research is therefore possible in at least three remaining areas.

If one focuses on tasks directly applicable in the L2 classroom (the top two research areas in Figure 1), it is necessary to examine the effects of other types of vocabulary processing tasks which have not been introduced in previous studies, yet induce semantic and structural processing. One example of such a task is a word association task. For example, it is possible to ask L2 learners to choose a word that is semantically or structurally similar to the target L2 word. When they are instructed to produce/choose semantically similar words, they must allocate their processing-resources to the semantic aspect of the target words, whereas when they are instructed to produce/choose structurally similar words, their processing-resources are allocated to the structural aspect. After the learning session, the same vocabulary posttests (e.g., L2 and L1 free recall, L1-to-L2 and L2-to-L1 cued recall) as in previous studies could be used as a first step.

On the other hand, if one focuses on the acquisition of fluent processing of newly learned L2 words (the right two areas in Figure 1), it is necessary to use measurements that could separate the processing of word form from its meaning. One such example is the so-called lexical decision task (LDT). Since lexical decision does not require semantic processing of the target, it would be an interesting test of the TOPRA model to examine how different types of vocabulary processing affect the accuracy and reaction time of the lexical decision regarding new L2 words. In this case, the same vocabulary processing tasks (e.g., pleasantness rating, letter counting) as previous studies could be used as a first step. These potential studies would be conceptual replications of previous studies in the TOPRA framework and should demonstrate the range of applicability of the TOPRA model.

Kida (2018a, 2018b) addressed these two issues; the preliminary analyses demonstrated that (1) the results of Barcroft (2002) were replicated when the word association tasks mentioned above were used and (2) structural processing of new L2 words led to more accurate and faster reaction times than semantic processing in the LDT. These studies demonstrated the possibility that the notion of the TOPRA model may be applicable in the L2 classroom and suggested that the prediction of the TOPRA model may be valid not only for the acquisition of word knowledge (i.e., word form, meaning, or form-meaning connection) but also for the acquisition of fluent processing of newly learned L2 words.

\section{References}

Barcroft, J. (2002). Semantic and structural elaboration in L2 lexical acquisition. Language Learning, 52, 323-363. doi:10.1111/0023-8333.00186

Barcroft, J. (2003). Effects of questions about word meaning during L2 lexical learning. The Modern Language Journal, 87, 546-561. doi:10.1111/15404781.00207

Vocabulary Learning and Instruction, 8 (1), 76-82. 
Barcroft, J. (2004). Effects of sentence writing in L2 lexical acquisition. Second Language Research, 20, 303-334. doi:10.1191/0267658304sr233oa

Barcroft, J. (2009). Effects of synonym generation on incidental and intentional L2 vocabulary learning during reading. TESOL Quarterly, 43, 79-103. doi:10.1002/j.1545-7249.2009.tb00228.x

Bialystok, E., \& Sharwood Smith, M. (1985). Interlanguage is not a state of mind: An evaluation of the construct for second-language acquisition. Applied Linguistics, 6, 101-117. doi:10.1093/applin/6.2.101

Craik, F. I. M., \& Lockhart, R. S. (1972). Levels of processing: A framework for memory research. Journal of Verbal Learning and Behavior, 11, 671-684. doi:10.1016/S0022-5371(72)80001-X

Craik, F. I. M., \& Tulving, E. (1975). Depth of processing and the retention of words in episodic memory. Journal of Experimental Psychology: General, 104, 268-294. doi:10.1037/0096-3445.104.3.268

Eckerth, J., \& Tavakoli, P. (2012). The effects of word exposure frequency and elaboration of word processing on incidental L2 vocabulary acquisition through reading. Language Teaching Research, 16, 227-252. doi: 0.1177/1362168811431377

Ellis, N. C. (2004). The processes of second language acquisition. In B. VanPatten, J. Williams, S. Rott, \& M. Overstreet (Eds.), Form-meaning connections in second language acquisition (pp. 49-76). Mahwah, NJ: Lawrence Erlbaum Associates.

Elgort, I., \& Warren, P. (2014). L2 vocabulary learning from reading: Explicit and tacit lexical knowledge and the role of learner and item variables. Language Learning, 64, 365-414. doi:10.1111/lang.12052

Hulstijn, J. H. (2001). Intentional and incidental second language vocabulary learning: A reappraisal of elaboration, rehearsal and automaticity. In P. Robinson (Ed.), Cognition and second language instruction (pp. 258-286). Cambridge University Press.

Hyde, T. S., \& Jenkins, J. J. (1969). The differential effects of incidental tasks on the organization of recall of a list of highly associated words. Journal of Experimental Psychology, 82, 472-481. doi:10.1037/h0028372

Jiang, N. (2000). Lexical representation and development in a second language. Applied Linguistics, 21, 47-77. doi:10.1093/applin/21.1.47

Joe, A. (2010). The quality and frequency of encounters with vocabulary in an English for academic purposes programme. Reading in a Foreign Language, 22, 117-138.

Kida, S. (2018a). Testing the TOPRA model with semantic and structural word association tasks: A conceptual replication of Barcroft (2002). Manuscript in preparation.

Kida, S. (2018b). Effects of task type and exposure frequency on the learning of new L2 words through reading. Manuscript in preparation.

Laufer, B. (1997). What's in a word that makes it hard or easy: Some intralexical factors that affect the learning of words. In N. Schmitt \& M. McCarthy (Eds.), 
Vocabulary: Description, acquisition and pedagogy (pp. 140-155). Cambridge University Press.

Laufer, B., \& Hulstijn, J. H. (2001). Incidental vocabulary acquisition in a second language: The construct of task-induced involvement. Applied Linguistics, 22, 1-26. doi:10.1093/applin/22.1.1

Laufer, B., \& Rozovski-Roitblat, B. (2011). Incidental vocabulary acquisition: The effects of task type, word occurrence and their combination. Language Teaching Research, 15, 391-411. doi:10.1177/1362168811412019

Laufer, B., \& Rozovski-Roitblat, B. (2015). Retention of new words: Quantity of encounters, quality of task, and degree of knowledge. Language Teaching Research, 19, 687-711. doi:10.1177/1362168814559797

Nation, I. S. P. (2001). Learning vocabulary in another language. Cambridge University Press.

Paribakht, T. S., \& Wesche, M. (1999). Reading and "incidental" L2 vocabulary acquisition: An introspective study of lexical inferencing. Studies in Second Language Acquisition, 21, 195-224. doi:10.1017/S027226319900203X

Schmitt, N. (2008). Review article: Instructed second language vocabulary learning. Language Teacher Research, 12, 329-363. doi:10.1177/1362168808089921 